\section{Atomic energy in Pakistan}

SIR - I wish Ehsan Masood had been more objective in his report on the Pakistan Atomic Energy Commission (PAEC) (Nature 376, 633; 1995). In contrast with his discussion of the Pakistan Agricultural Research Council, there is no mention of how many papers have been produced by PAEC scientists, or the judgement their work receives from their colleagues through citations. Instead, Masood quotes the description by the director of PAEC's Institute for Nuclear Science and Technology (PINSTECH) of his staff as "the largest collection of trained, motivated and research oriented scientists in the country".

It is not that the publication figures are hard to find. A quick glance at the PINSTECH Silver Jubilee Technical Report shows that its staff has managed to produce only 679 papers in international journals in the past 25 years. This amounts to barely 25 papers a year, from the "largest collection of trained... scientists" and is hardly the kind of performance that justifies the label of "jewel in the crown" that the author confers.

On the other hand, the author dwells on the technological achievements of the PAEC and PINSTECH, claiming that PINSTECH is "in the midst of building" a 300-MW reactor at Chashma, "with the help of China". The implied division of labour is clear: PAEC is doing the building and the Chinese are lending a helping hand. Only the PAEC would describe it thus.

Independent sources such as Nuclear News (February 1992) described the deal as one where "China will provide a 300 MW pressurised water reactor to Pakistan". The reactor, which Nuclear News describes as an "import", is based on Qinshan-1, which China considers to be an "indigenous design". The Far Eastern Economic Review (23 January 1992) in its report puts it as follows: "An agreement for China to build a nuclear power-station in Pakistan." The details it gives are that the Chinese are to "install" the reactor, "supply nuclear fuel to run it" and "transfer nuclear technology to Pakistan".

In fact, the Chinese are selling Pakistan a largely untested Chinese-designed reactor for a "give-away" price of US\$500 million (according to The Far Eastern Economic Review) as part of their plan to get into the nuclear supply business. There is no way this could be described as the PAEC being "in the midst" of building anything except a cosy little empire, one in which there is no financial accountability, no independent scientific oversight of the programmes, and contempt for parliament.

The reason that the PAEC is allowed to get away with this is simple. It is hard for many in Pakistan to challenge the PAEC because of the link with the nuclear weapons programme, with the PAEC only too happy to wrap itself in the cloak of national security. Your report, incidentally, omits mention of the secret 40-MW plutonium production reactor that Pakistan has been trying to build at Khushab, a project that came to light during the visit of the prime minister of Pakistan, Benazir Bhutto, to the United States earlier this year (Washington Post 8 April 1995).

\section{Zia Mian}

Sustainable Development Policy Institute, PO Box 2342,

Islamabad, Pakistan

SIR - Ehsan Masood's report on "Science in Pakistan" (Nature 376, 631-638; 1995) deserves a more extensive response than can be published as a simple letter. I shall therefore limit myself to a single pointthe mispresentation of the role of Professor Abdus Salam, a Nobel prizewinner, in Pakistani science.

The writer makes three claims. He would have us believe that Salam pushed particle and nuclear physics at the expense of more "practical" sciences, that he succeeded in foisting these views on Pakistani universities to their detriment, and that he voluntarily exiled himself from the country of his birth.

In fact, Salam rarely missed an opportunity to urge Pakistani physicists and graduate students to work in practical areas of physics such as condensed matter, laser, plasma and so on. Coming as it did from a Nobel prizewinner in high-energy physics, I found this view a little unsettling at times because high-energy physics is my field and I do believe it to be important. But Salam was firm on this point in a discussion that I had with him almost a decade ago. Pakistan needs technology right now, he said, so let's leave theoretical physics to a small number of truly gifted people.

Masood goes on to credit, or rather impugn, Salam with "guiding the graduate physics programme at Quaid-i-Azam University" (Pakistan's leading university) and claims that "Pakistan's university physics departments are a monument to Salam's influence". No one would wish for such an awful monument; if Salam had indeed influenced our physics departments, maybe they would not now be so intellectually impoverished. Far from guiding or founding our physics programme, Salam has never even visited Quaid-i-Azam University, where I have been teaching since 1973 .

I would like to make it clear that this has not been by choice on his part, or on the part of the faculty. After Salam received the Nobel prize in 1979, several of the physics faculty wanted to invite him to a symposium at the university. But when the Islami-Jamiat-i-Ealaha, the student wing of a fundamentalist political party, threatened to disrupt the meeting violently if he was invited, the invitation was withdrawn. This group and its parent party consider Salam to be a heretic because he belongs to the Ahmadiyya sect.

This relatively minor episode brings me to my third point. Masood reports the allegations of Salam's detractors that he abandoned his native country for the West. Having worked as a physicist in Pakistan for more than 20 years, it is my considered opinion that Salam's talents would have rapidly atrophied in the intellectual desert of Pakistani universities. Had he stayed on in Pakistan, Salam could never have blossomed into a leader of the most difficult and competitive field of scientific endeavour. Nor could he have founded the International Centre for Theoretical Physics in Trieste, Italy, an invaluable source of help to science development in many countries. As a resident Pakistani, Salam would have had negligible influence in either science policy or institution making.

There is a still graver issue: given the violence regularly and systematically perpetrated against the members of his religious community, it is far from clear that Salam could have survived even physically. A year ago, on the night of 9 October 1994, I rushed the bullet-torn body of my departmental colleague and next-door neighbour, Dr Naseem Baber, to a hospital in Islamabad. He too was a member of the Ahmaddiyya sect.

\section{Pervez Hoodbhoy}

Physics Department,

Quaid-i-Azam University,

Islamabad 45320,

Pakistan

\section{Residents' rights}

SIR - In response to my earlier letter, Michel Cuénod, the secretary general of the Human Frontier Science Program (HFSP), points out (Nature 377, 192; 1995) that nationals of any country can apply for HFSP funding as "co-applicant" as long as the principal applicant is a citizen of one of the member states.

But there is an important principle at stake here. In spite of their lack of citizenship, permanent residents are, nevertheless, allowed to pay taxes. HFSP member states use these tax revenues to contribute to the programme. So should not permanent residents enjoy the same access to HFSP funding as citizens?

Michael Lardelli

Department of Developmental

Neuroscience,

Uppsala University,

Box 587, BMC,

75123 Uppsala, Sweden 